Material beginnings

Ian Walmsley

Nonlinear Optics: Principles, Materials, Phenomena, and Devices. Editor Takayoshi Kobayashi. Gordon and Breach. 4/yr. \$640 (corporate); £315 (institutional); $£ 60, \$ 111$ (personal).

IT is some 60 years since the first prediction of a nonlinear optical effect was made, and some 30 years since such phenomena were first observed. Given the long history of this branch of physics, and the prodigious literature on the subject, it is surprising that it has taken so long for a journal named after the field to spring forth. Perhaps part of the answer is that nonlinear optics has progressed from being an endeavour primarily for the laboratory to the point where it has serious practical implications for devices devoted to information processing, notably optical communications systems. It is thus important that appropriate nonlinear media are available, and a considerable part of current research in nonlinear optics is concerned with the development of such materials.

The first few issues of Nonlinear $O p$ tics are, in fact, largely about materials research, as is perhaps natural for a journal that is a part of a materials science publication (it is part B of Molecular Crystals and Liquid Crystals Science and Technology). This emphasis is likely to be its strength, although it is the avowed aim of the journal also to provide a forum for research in principles, phenomena and devices related to nonlinear optics. These areas are, however, already well serviced by other journals such as Journal of the Optical Society of America B, Physical Review A, Optics Letters, Optics Communications and Applied Physics Letters, and it is unlikely that a new publication will usurp its more well established brethren. The question is really whether it will complement them.

On the other hand, papers on research in nonlinear optical materials have been more widely dispersed, turning up in chemistry and chemical engineering journals, as well as in journals devoted to solid-state and applied physics. So it is appropriate and timely to provide a focused repository for this information, and it is this niche that the present journal is likely to fill, provided that the content can be broadened to include a larger representation of solid-state materials, especially bulk and microstructure semiconductors.

The journal has had an auspicious beginning. The editorial representation is both geographically broad and technically comprehensive, as is appropriate for an interdisciplinary journal. The issues so far have contained mainly lengthy research articles (10 to 20 pages apiece). There is no explicit statement about the publication of comments (none has appeared, but they are not prohibited) and there are no editorial or review sections. The production quality is high, and the cost reasonably low, considering that there are no page charges. The journal in its present form provides a useful addition to an optics research library.

Ian Walmsley is in the Institute of Optics, University of Rochester, Rochester, New York 14627, USA.

\section{Optical activity}

\section{Keith Blow}

Soviet Lightwave Communications. Editor-in-chief A. M. Prokhorov. IOP/ Academy of Sciences of the USSR. 4/yr. $£ 120, \$ 215$.

A WeStern journal devoted to scientific publications from the Eastern bloc is one that we can readily make room for. Soviet Lightwave Communications will publish papers in the areas of optical communications, guided wave optics and nonlinear optics. Overall, the journal has the feel - in style, quantity and content - of the Journal of Physics series, also published by IOP. Papers are refereed by one Western and one Eastern expert, and most seem to be published in less than six months from receipt. In his opening leading article, Prokhorov says, "we intend to publish the latest and best of Soviet fibre and integrated optics research". So far, the journal is living up to this expectation. More than half of the papers have come from the well known General Physics Institute in Moscow, but I am sure this will change as the reputation of the journal becomes established and spreads throughout Eastern Europe.

The first few issues contain several important papers that have set the standard for others to follow. For example, the first issue contains the definitive theory of long-range soliton interactions in optical fibres, a problem of relevance to transoceanic soliton communications systems. However, this is just one of many articles involving optical fibres, ranging from papers on ultrashort (less than 100 femtosecond) pulse production and propagation to papers on industrial production of fibre in the former Soviet republics. Several articles on the newer field of waveguides in highly nonlinear materials such as KTP have also appeared. All these topics are being actively pursued in the West and so we can reasonably expect the journal to become a useful source of information for all optical physicists and engineers. $\square$

Keith Blow is at British Telecom Development and Procurement, BT Laboratories, Martlesham Heath, Ipswich IP5 7RE, UK.

\section{Images, signals and circuits}

\section{David Holburn}

CVGIP: Graphical Models and Image Processing. Editors-in-chief Norman I. Badler and Rama Chellappa. Academic. $6 / y r$. UK $£ 172$, elsewhere $\$ 294$ (institutional).

CVGIP: Image Understanding. Editor-inchief Linda G. Shapiro. Academic. 6/yr. UK £219, elsewhere $\$ 317$ (institutional).

Journal of Visual Communication and Image Representation. Editors-in-chief Yehoshua Y. Zeevia and T. Russell Hsing. Academic. 4/yr. UK £107, elsewhere $\$ 154$ (institutional); UK $£ 56$, elsewhere $\$ 81$ (personal).

TECHNOLOGICAL developments over the past 20 years have made computer graphics, computer processing of images and computer vision popular topics for investigation. Although these three activities have arisen from quite distinct roots, they overiap to a certain extent. Graphical displays are clearly important in image processing, computer vision or visual communication, while many problems in computer graphics require techniques from image processing for their solution. More recently, several new image and communication technologies have emerged, such as high-definition television, multimedia, satellite imagery and medical imaging. For many years now, Computer Vision, Graphics and Image Processing (CVGIP) has served admirably as a forum for workers in these fields. CVGIP has an excellent pedigree, running to 52 volumes, is well presented, and is essential reading for anyone with an interest in imaging or graphics.

But the pace of research eventually led the editors to consider whether the journal was trying to cover too much. The decision was taken to split CVGIP into two separate journals, each aimed at a different area. Two of the journals reviewed here are direct descendants, inheriting the quality of content and presentation associated with $C V G I P$; but each is also a new journal in its own 